\title{
US senator alleges FDA tried to prevent Adderall XR withdrawal in Canada
}

\author{
Published at www.cmaj.ca on Mar. 9, 2005.
}

Health Canada's discussions with its US counterpart about a drug it later pulled from the market were "irrelevant" and had no bearing on its decision, despite allegations by an influential US senator, says a senior Canadian regulator.

Dr. Siddika Mithani, associate director general of Health Canada's Therapeutic Products Directorate, refused to tell CMAJ how many times and when Health Canada officials met or held teleconferences with US Food and Drug Administration to discuss Adderall XR (amphetamine salts).

On Feb. 9, Health Canada pulled the drug, which is prescribed for attention deficit hyperactivity disorder, after evaluating data from about 20 sudden deaths and 12 strokes in both children and adults taking the drug. All of the deaths took place in the US.

US Senator Chuck Grassley, chair of the US Senate finance committee, has accused FDA officials of asking Health Canada not to withdraw the drug because they feared it would reflect badly on their safety record. The FDA chose to keep Adderall XR on the market.

Grassley held hearings investigating the FDA after a senior drug reviewer, David Graham, accused the agency of ignoring his advice about safety concerns relating to $\mathrm{COX}-2$ inhibitors, including rofecoxib (Vioxx) and other drugs.

In a letter dated Feb. 10 to Dr. Lester Crawford, then acting head of the FDA, Grassley states that Health Canada and - FDA officials held a series of meeting concerning Adderall XR. "Information conveyed to my staff suggests that during a recent Adderall meeting, one or more FDA employees requested that the Canadian government refrain from suspending the use of Adderall XR because there was concern that FDA could not handle another 'drug safety crisis'," Grassley wrote.

"Unfortunately, such allegations raise additional concerns about the culture at the FDA."

Mithani maintains no one from the FDA asked Health Canada to keep Adderall XR on the market.

"That is not true," she says of Grassley's allegations. "You know, regulators don't ask each other not to do stuff. Everybody's decision is independent. There was not talk about this at all."

The US senator has asked the FDA to provide the committee with details, including the time, date, and minutes from all meetings and teleconferences between the FDA and Health Canada (or any representative from the Canadian government), as well as any pertinent correspondence.

Asked to do the same, Mithani refused. Health Canada did discuss "psychostimulants, generally, risks with this type of drug, in this indication" and how it would be monitoring similar drugs, as well as "proprietary information," she says.

"The relevancy here for Canada is that our regulatory decision was based on that regulatory submission, and this ... was an independent decision based on the data that we had," Mithani says. "What is really not relevant is who we talked to."

Health Canada made its decision because of the catastrophic nature of the adverse events, the department stated. "When we looked at the data, we determined that it was not possible to mitigate the risks or the potential risks by just changing the label," says Mithani.

But, at the request of Shire Pharmaceuticals, Adderall XR's manufacturer, Health Canada will convene an expert panel, known as the New Drug Committee, to review the process. Once the 3member committee will issue recommendations to Health Minister Ujjal Dosanjh, who can reverse the decision. This process is available to all manufacturers in similar situations.

“There's been no causality associated with Adderall XR or Adderall and the sudden death incidents or any of the reported incidents," says Matt Cabrey, Shire's senior manager of corporate communications. "Essentially that's what the US FDA has said as well."

The adverse events, including the deaths, occurred between 1996 and 2003. Health Canada approved Adderall XR in January 2004.

Shire's original application for Adderall XR did not contain information about any sudden deaths, says Mithani. "It was not part of the application. It should have been part of the application."

Shire insists the information was available to Health Canada.

"The data that were originally submitted to Health Canada in order for them to approve Adderall XR in January 2004 were all incidents of adverse events on Adderall XR," Cabrey said in an interview.

But, in a later interview, Cabrey said the Therapeutic Products Directorate, which approves new drugs, "may not have had all the data." He said the data may have gotten mislaid within Health Canada and never made it to the original reviewers.

Mithani refused to discuss whether or not Shire submitted information about adverse events to one department in Health Canada, but not to the directorate. - Laura Eggertson, CMAJ

A transcript of part of the interview with Dr. Mithani appears at www.cmaj.ca 